\title{
An Automatic ROI of The Fundus Photography
}

\author{
Jufriadif Na`am¹, Johan Harlan², Irawadi Putra ${ }^{3}$, Romi Hardianto ${ }^{4}$, Mutiana Pratiwi ${ }^{5}$ \\ 1,4,5 Faculty of Computer Science, Universitas Putra Indonesia YPTK Padang, Indonesia \\ ${ }^{2}$ Faculty of Computer Science, Universitas Gunadarma Depok, Indonesia \\ ${ }^{3}$ Ophthalmologist, Rumah Sakit Stroke Nasional Bukittinggi, Indonesia
}

\begin{tabular}{l} 
Article Info \\
\hline Article history: \\
Received May 30, 2018 \\
Revised Jul 28, 2018 \\
Accepted Aug 3, 2018 \\
\hline
\end{tabular}

\section{Keyword:}

Automatic

Fundus

Medical image

Region of interest (ROI)

The posterior pole of retina

\begin{abstract}
The Region of interest (ROI) of the fundus photography is an important task in medical image processing. It contains a lot of information related to the diagnosis of the retinal disease. So the determination of this ROI is a very influential first step in fundus image processing later. This research proposed a threshold method of segmentation to determine ROI of the fundus photography automatically. Data to be elaborated were the fundus photography's of 13 patients, captured using Nonmyd7 camera of Kowa Company Ltd in Dr. M. Djamil Hospital, Padang. The results of this processing could determine ROI automatically. The automatic cropping successfully omits as much as possible the non-medical areas shown as dark background, while still maintaining the whole medical areas, comprised the posterior pole of retina captured through the pupil. Thus, this method is helpful in further image processing of posterior areas. We hope that this research will be useful for researchers.
\end{abstract}

Copyright $(2) 2018$ Institute of Advanced Engineering and Science. All rights reserved.

\section{Corresponding Author:}

Jufriadif Na`am,

Faculty of Computer Science,

Universitas Putra Indonesia YPTK Padang,

Jl. Raya Lubuk Begalung Padang, 25221, Indonesia.

Email: jufriadifnaam@gmail.com

\section{INTRODUCTION}

Fundus photography involves activities to capture fundus images, which shows the inner posterior part of the eye, comprised of the retina, the optic disc, the macula as the main structures in a fundus image. Fundus image contains lots of information for ophthalmologists concerning many retinal alterations affected by ocular as well as extra-ocular diseases or health disturbances, such as glaucoma, macular degeneration, papil edema, retinal detachment, diabetic retinopathy, diabetic maculopathy, hypertensive retinopathy, etc [1]-[5]. Formerly fundus photography were seldom to be performed, as most ophthalmologists prefer to have direct funduscopy examination, however in the era of e-health and the development of electronic health records nowadays, there are greater tendencies to keep digital fundus images for later examinations as well as medical documentations.

View of the posterior pole of retina is obtained by passing light rays through dilated pupil, and fundus image is then captured by using fundus camera, an apparatus designed based upon the former concept of ordinary direct ophthalmoscope. Fundus image to be obtained is circular in shape, but usually laid upon dark rectangular background as shown in Figure 1. When analyzing objects in an image, it is necessary to distinguish the objects of interest from the background [6], [7]. The dark background is not necessary for the ophthalmologists, whose Region of Interest (ROI) only include the circular fundus image. The objective of this study is to design digital image process to obtain the ROI of circular fundus image automatically. The background area can either be removed or filled with preferred colour of the ophthalmologist. We expect that the results will make it easier for the ophthalmologist to analyze and improve the accuracy of analyzing the objects in the processed fundus image. In the field of medical imaging, radiologists are more interested in 
ROI than the entire image area, because it is part of the image that contains important information as an object of analysis [9]. In addition, the ROI measure can affect the sensitivity and specificity of the classification in the accuracy of the analysis [10].

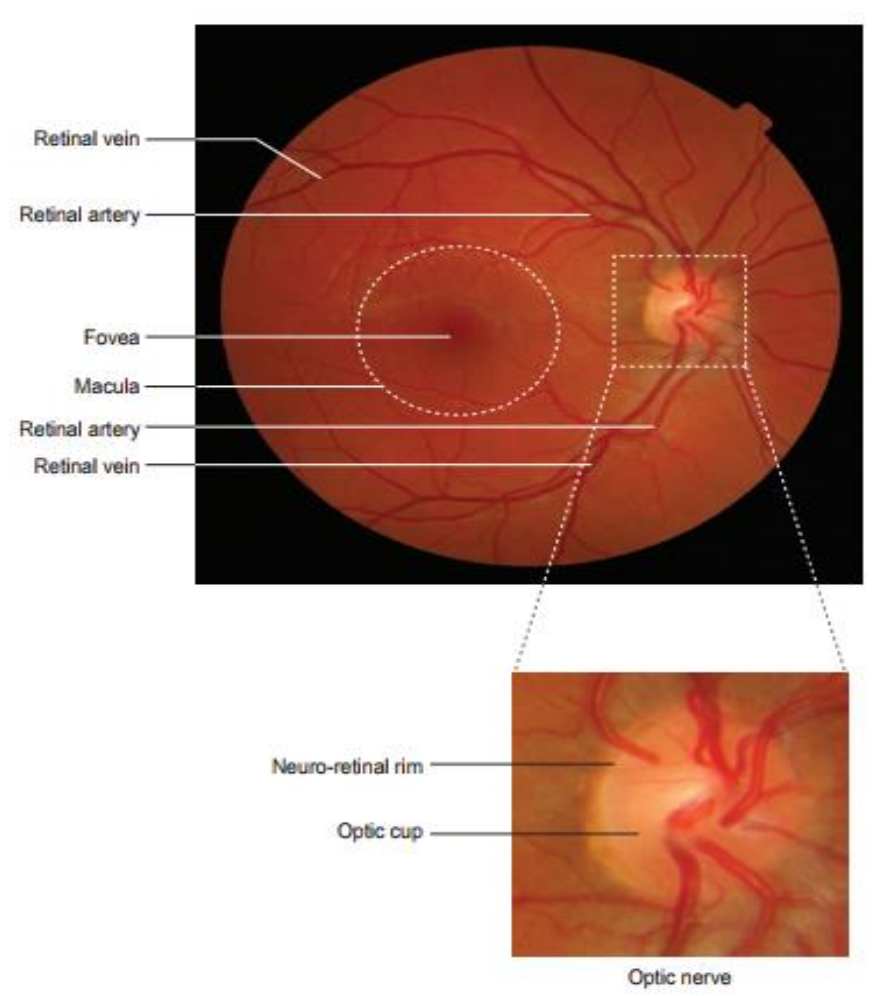

Figure 1. Normal fundus image structure [8]

Here is some study that performs image processing on the selection of ROI on medical images. Aribi et al conducted a study of automatic ROI on the kidneys on the image scintigraphic images using HOG3D descriptor [11]. Shan et al used the ROI segmentation mask method on the liver in the image of Computerized Tomography Scan (CT-Scan) and the brain in Magnetic Resonance Imaging (MRI) [12]. Gaidel determines the ROI of the lung automatically on CT-Scan images using a heuristic image segmentation algorithm [13]. Sharma conducted a study to choose the correct size of rectangular ROI manually to differentiate between fat and dense tissue in breast image [10]. Similarly, Santony et al [14] and several studies of Na'am et al selectively selected ROI areas for medical images of the square [15]. Wu et al conducted a study to select ROI area automatically using the segmentation method in a brain image [16].

The following research is the use of ROI in fundus image processing to analyze various diseases. Many studies that define ROI based on processing needs by cropping [17-24]. Zahoor et al conducted a study of optical disc space ROI taking with Polar Transform method [25]. Haleem et al conducted a study of optical disc space ROI taking with Region Classification Model (RCM) [26]. Karusulu conducted a research to detect optical disk area automatically using Multi-level Thresholding method [27]. Mukherjee et al conducted a research to localize the optic disk region based on a parameterized membership function defined on the cluster regions and the predicted convergence point of the retinal vasculature [28]. From some research above, hence required a method automatically to determine ROI in fundus image. The goal is to further improve the objectivity and accuracy of the analysis in the fundus image.

\section{RESEARCH METHOD}

Many diseases that can be analyzed in the fundus image so that accuracy in image processing is important. One of the indicators to improve the accuracy of the image processing is to limit the image area to the required part only, which is the Region of Interest (ROI). The result of this study performs the automatic creating of ROI of the fundus image. 
The sample to be processed consists of 13 fundus images of 13 patients in the Central General Hospital (RSUP) Dr. M. Djamil Padang. The images were captured by using a Nonmyd7 brand fundus camera of Kowa Company Ltd in Joint Photographyic Experts Group (jpg) format. Furthermore, the images were processed with Matlab R2017a software. Stages of the image processing are show in Figure 2.

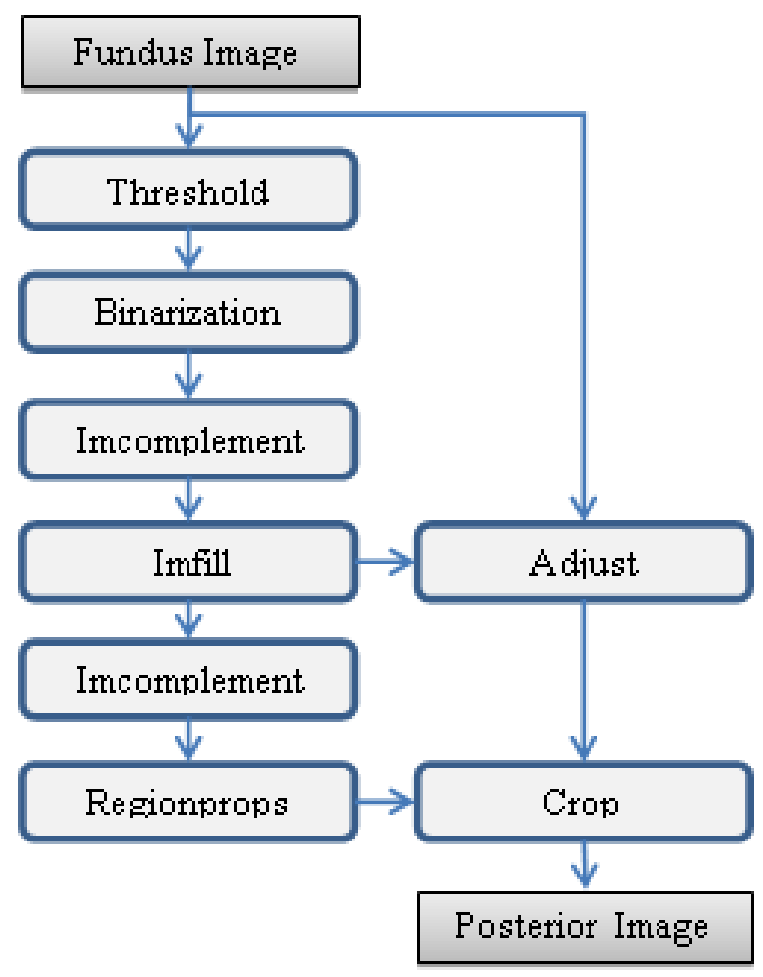

Figure 2. Stages of the process

\subsection{Threshold}

Threshold is the pixel grayscale value limit to distinguish the background of the object observed in the image. The equations used in this study are as follows:

$$
T=\frac{\text { multithresh }(\text { Im })}{255 \times \operatorname{uint}(\operatorname{Im})}
$$

where: $T$ : threshold value

multithresh : function to find many groups of gray

Im : input image

255 : maximum value of grayscale

uint : bit of memory each grayscale value.

\subsection{Binarization}

The binary process is performed to convert a grayscale image pixel value between 0 to 255 to a binary image with a pixel value of 0 or 1 . Conversion process based on the threshold value specified above. The equation is as follows:

$$
I b_{(r, c)}=\left\{\begin{array}{l}
0, \operatorname{Im}_{(r, c)}<T \\
1, \operatorname{Im}_{(r, c)} \geq T
\end{array}\right.
$$


where: $I b$ : binary image

$$
\begin{aligned}
& r \text { : row of pixel } \\
& c \text { : column of pixel }
\end{aligned}
$$

\subsection{Imcomplement}

Imcomplement process is reversing the image pixel value. The pixel value is 0 becomes 1 and the value 1 becomes 0 . The equation is as follows:

$$
I c=I m^{\prime}
$$

where: Ic: imcomplement image

\subsection{Imfill} follows:

Imfill process is used to equalize the pixel value surrounded by the same value. The equation is as

$$
I l=\left\{\begin{array}{c}
I c(r, c), \text { if }(r, c) \text { is on the border } \\
\text { of Icotherwise } \\
0
\end{array}\right.
$$

where: $I l$ : imfill image

\subsection{Regionprops}

The process of regionprops serves to represent the object area in the image into a square (region) based on a set of pixels of value 1 (white). The Matlab statement is follows:

\begin{tabular}{l}
\hline \hline Code of regionprops commands \\
\hline Input: $I l$ \\
Output: $t$ Box \\
$\qquad \begin{array}{ll}\text { Initialization } \text { reg } \\
\text { reg } & =\text { regionprops }(I l) ; \\
t B o x & =\text { reg. BoundingBox; }\end{array}$ \\
\hline
\end{tabular}

\subsection{Adjust Bacground}

Background adjust is converting the background pixel value to a value that does not affect for further image processing. Commonly, type of background pixel is using 0 for black or 255 for white, but can also use other types such as red, blue or green. The equation is as follows:

$$
I a_{(r, c)}=\left\{\begin{array}{c}
n, I l_{(r, c)}=1 \\
I l_{(r, c)}
\end{array}\right.
$$

where: Ia: image result

$$
n: 0 \text { for black or } 255 \text { for white }
$$

\subsection{Crop}

Crop is cutting the square-shaped area automatically to the image adjusted background. The area of crop is accommodated the regionprops result. The Matlab statement is follows:

Code of crop commands

Input: $I a, t B o x$

Output: Iroi

Iroi $=\mathrm{imcrop}(\operatorname{Ia}, t B o x)$; 


\section{RESULTS AND ANALYSIS}

There were 13 fundus images processed in this study at Dr. M. Djamil Hospital, Padang. However, only one of them is presented here. Specification of fundus camera and the examination is shown in Table 1. The fundus camera is connected to a Windows desktop with installed Kowa's VK-2 digital imaging software, allowing automatic image saving for viewing at user's convenience. The VK-2 digital imaging software capture and stores retinal photographs taken from Kowa retinal camera as well as images from other sources including a scanner. The shoots can be done at 3 internal fixation points, i.e. temporal, central, and nasal point to ensure better retinal coverage. Result of the shoots is shown in Figure 3.

Table 1. Specification of Fundus Examinations [29]

\begin{tabular}{|c|c|}
\hline Category & Description \\
\hline Design & Reflective imaging using white light \\
\hline Pupil & Nonmydriatic \\
\hline Field of view & $40^{0}$ \\
\hline Image sensor/display & 12 MP digital camera \\
\hline Additional features & Optic nerve head color, red-free images, pseudo-3D display \\
\hline
\end{tabular}

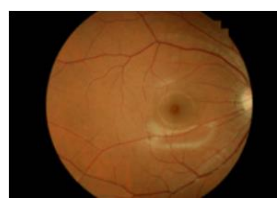

(a)

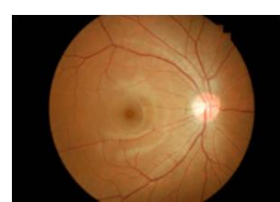

(b)

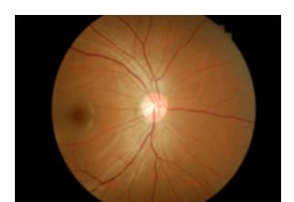

(c)

Figure 3. Shoot, (a) temporal, (b) central, (c) nasal [30]

First the retina is illuminated by white light and being examined in full colour. Then the illumination light is filtered to remove red colours, which aimed to improve the contrast of vessels and other structures. Various fundus structures can be better visualized by using limited spectral range of the illumination light. Images to be generated in each step of the process can be seen in Figure 4.

Figure 4.a shows the input image, which type is true colour, having 3696x2448 pixel. Further process was to calculate threshold value. Using this threshold value, the image was converted into a binary one. The binary image was saved into a new image with a new file name. The aim of this conversion was to change the value of the pixel in the interested object to 1 (white) so that the interested object can be distinguished from its background. The resulted image of this process is shown in Figure 4.b.

The resulted binary image was then processed through imcomplementing. Imcomplementing process reversed the pixel value from 0 to 1 and from 1 to 0 . The resulted imcomplement image is shown in Figure 4.c. The aim was to map the pixel in interested object into the imfill process. The imfill process aims to convert all the pixels surrounded by pixels of 0 value in the interested object to 0 . So the whole pixel of the interested object became 0. The result of this process can be seen in Figure 4.d.

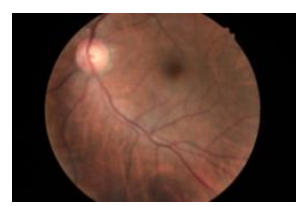

(a)

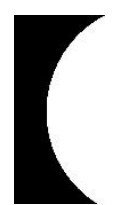

(b)

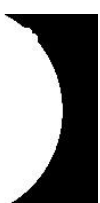

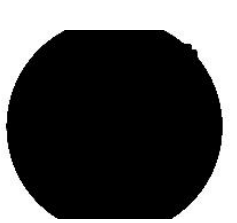

(c)

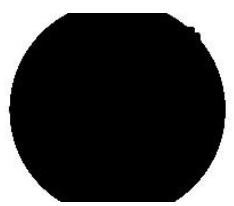

(d)

Figure 4. Images in the process, (a) input image, (b) binarization image, (c) imcomplement image, (d) imfill image

The next process is the background process of the input image. All pixels in the same input image position as imfill image with pixel value equal to 1 were then converted to a constant value. The value of this constant determines the colour of the background part in the input image. The background pixels value can be converted according to the user's volition. White with the element of pixel value Red=255, Green=255, and Blue $=255$. Black with the element of pixel value Red $=0$, Green=0, and Blue $=0$. Red with the element of 
pixel value $\operatorname{Red}=255$, Green=0, and Blue $=0$. Green with the element of pixel value Red=0, Green=255, and Blue $=0$. Blue with the element of pixel value $\operatorname{Red}=0$, Green=0, and Blue $=255$.

The imfill image was also processed to obtain the ROI matrix. First, the imfill image was converting to imcomplement and taken the matrix area containing the object of posterior retina only by using regionprops command. Furthermore, the input image has been converted background value crop in accordance with the results of regionprops as the area of the interested object. The results of final process can be seen in Figure 5.

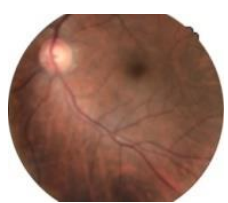

(a)

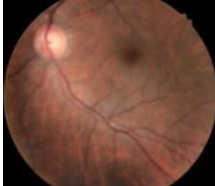

(b)

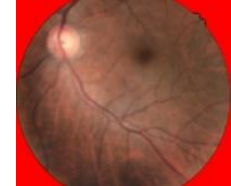

(c)

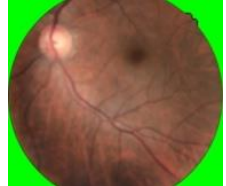

(d)

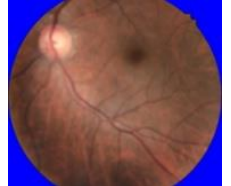

(e)

Figure 5. Image of an automatic ROI result, (a) white background, (b) black background, (c) red background, (d) green background, (e) blue background

The final result image in this processing is the ROI object on a square area. Because digital images stored in the 2-dimensional matrix while the fundus is in a circular shape, so this digital image still contains a minimal background area that is not part of the medical image. These background pixel values are adapted to the next process so as not to affect for next image processing of posterior retina.

There are a lot of definitions for the Region of interest (ROI) of medical image, which mainly depend upon the intention of the researcher for further study. A common-purpose definition of ROI of medical image can be stated as a subset of a medical image, identified for a particular purpose. In the funduscopy examination, it can be done just as part of a routine physical examination. However, most of the time, the ophthalmologist may have a certain purpose to check the fundus image. Fundus imaging can serve as a critical adjunct to the diagnosis, monitoring, and treatment of numerous ocular, as well as general diseases [31]. Screening of the retina by fundus photographyy may detect ocular diseases, such as macular degeneration, the first and third most important causes of blindness in the developed world. It may also detect complications of systemic diseases which also affect the retina, including diabetic retinopathy from diabetes, the second common cause of blindness in the developed world, hypertensive retinopathy from cardiovascular disease, and multiple sclerosis [32].
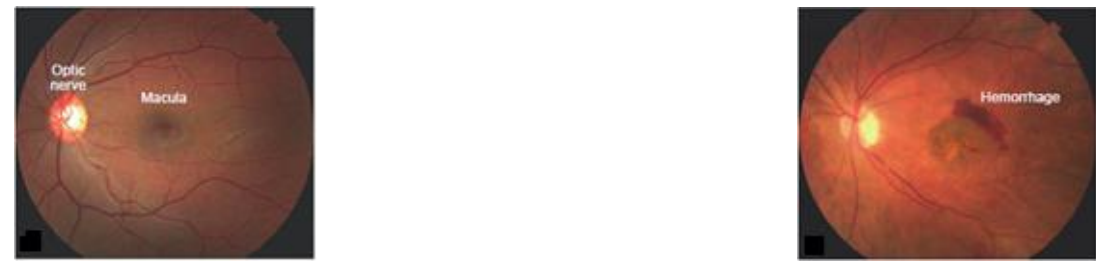

Figure 6. Fundus photography from a normal eye (left) and eye with age-related macular degeneration (right) [33]

In general if the ophthalmologist has already known what he/she is looking for, ROI of fundus photography depends upon the function of the image for him/her. In most studies, ROI of medical image comprises just comprises a subset of a medical image. However, in fundus photography image, the whole part of the image that regarded as medical part is all can be seen through the pupil. Actually the outer part of the pupil includes iris with its pattern of vascularization, nevertheless strong illumination only emitted through pupil, while inadequate illumination to the iris makes it just being dark background, as if it is not any part of a medical image.

Human pupil which will determine the circular form of the fundus is not always perfectly round. Although all of the fundus images in our sample seem in good circular form, we must create a program that is also applicable to fundus images which are not perfectly round. There are several methods in medical image processing that can be used to obtain the ROI. In the Related Work section we have mentioned several 
methods of segmentation in image processing to obtain ROI of medical image [11-16]. We propose here a simple method of thresholding technique to partion the fundus photography into foreground (medical part) and background (non-medical part) and create an automatic cropping of the fundus image. Nevertheless, in our state-of-the-art knowledge to create automatic cropping in medical imaging, it will be quite difficult if not impossible to obtain a circular form of ROI of medical image.

Hirano and Tsumoto (2004), using discretized attribute values were able to construct anatomically shape ROI of medical image captured by MRI or CT Scan apparatus. Yet the attributes actually split the medical image into 3 regions, the positive, the negative, and the boundary ones, hence they just create a rough representation of ROI [34].

\section{CONCLUSION}

From the result of this study it is concluded that the process elaborated can automatically crop the interested object in the image obtained from fundus photography. We have successfully create a program to automatically cropping fundus photography for general purpose intention. The cropping result is the region of interest (ROI) of the fundus image. It makes us easier to crop the next image with the aim to analyze the retinal disturbances. So this research will be useful for researchers to perform fundus image processing in analyzing patient illness.

\section{ACKNOWLEDGEMENTS}

We would like to thank for Department of Radiology, M. Djamil Center General Hospital, Padang, which has allowed the use of the data in this study.

\section{DISCLOSURE STATEMENT}

No potential conflict of interest was reported by the authors.

\section{REFERENCES}

[1] U. Farooq, et al., "Improved automatic localization of optic disc in Retinal Fundus using image enhancement techniques and SVM", IEEE International Conference on Control System, Computing and Engineering (ICCSCE), pp. 532-537, Nov. 2015.

[2] M. D. Abràmoff, et al., "Retinal Imaging and Image Analysis", IEEE Reviews in Biomedical Engineering, vol. 3, pp. 169-208, 2010.

[3] J. S. Swamy, et al., "Implementation of Image Enhancement Techniques for Vein Patterns in Eye", IEEE International conference on Signal Processing, Communication, Power and Embedded System (SCOPES), pp. 390395, 2016.

[4] F. Bandello, et al., "Medical Retina", ESASO Course Series, Karger, vol 1, pp 6-10, 2012.

[5] M.P.A. Robert, et al., "Infrared Fundus Photography in a Case of Acute Macular Neuroretinopathy," IETE Journal of Research., vol. 32, no. 4, pp. 200-202, Jul 2009.

[6] C. Stolojescu-Crisan and Ş. Holban, "A Comparison of X-Ray Image Segmentation Techniques," Advances in Electrical and Computer Engineering, vol. 13, no. 3, pp. 85-92, 2013.

[7] W. Gunawan, et al., "Fuzzy Region Merging Using Fuzzy Similarity Measurement on Image Segmentation," International Journal of Electrical and Computer Engineering (IJECE), vol. 7, pp. 3402-3410, Sep. 2017.

[8] S. Ghosh, et al., "Fundoscopy Made Easy", Churchill Livingstone, Elsevier, 2010.

[9] S. A. Elhannachi, et al., "Adaptive Medical Image Compression Based on Lossy and Lossless Embedded Zerotree Methods," Journal of Information Processing Systems, vol. 13, No. 1, pp. 40-56, 2017.

[10] V. Sharma, "Comparative Analysis of Region of Interest of Different Sizes for Breast Density Classification," International Journal of Medical Research \& Health Sciences, vol. 7, no. 3, pp. 76-84, 2017.

[11] Y. Aribi, et al., "Automatic Definition of Regions of Interest on Renal Scintigraphic Images", In AASRI Procedia, vol. 4, pp. 37-42, 2013.

[12] S. Shan, et al., "Unsupervised End-to-end Learning for Deformable Medical Image Registration", ArXiv e-prints, vol. 14 , no. 8 , pp. 1-11, 2015.

[13] A. Gaidel, "Method of automatic ROI selection on lung CT images," Procedia Engineering, vol. 201, pp. 258-264, 2017.

[14] J. Santony and J. Na'am, "Infiltrate Object Extraction in X-ray Image by using Math-Morphology Method and Feature Region Analysis," International Journal on Advanced Science, Engineering and Information Technology, vol. 6, no. 2, pp. 239-244, 2016.

[15] J. Na am, et al, "Detection of proximal caries at the molar teeth using edge enhancement algorithm," International Journal of Electrical and Computer Engineering (IJECE), vol.8, no.5, pp. 3259-3266, 2018.

[16] J. Wu, et al, "A fast and accurate segmentation method for medical images," Electronic Imaging, Visual Information Processing and Communication VIII, pp. 38-43, 2017. 
[17] E. Emary, et al, "Multi-objective retinal vessel localization using flower pollination search algorithm with pattern search," Springer-Verlag Berlin Heidelberg, vol. 11, no. 3, pp. 611-627, 2017.

[18] A. A. Salam, et al., "Automated detection of glaucoma using structural and non structural features", SpringerPlus, vol. 5, n0. 1, pp. 1-21, 2016.

[19] J. Sigut, et al, "Contrast based circular approximation for accurate and robust optic disc segmentation in retinal images," PeerJ, 5:e3763, 2017.

[20] L. S. Jack, et al, "Spatial agreement between Goldmann visual field defects and fundus autofluorescence in patients with birdshot chorioretinopathy," Journal of Ophthalmic Inflammation and Infection, vol. 6, no. 1, pp. 1-7, 2016.

[21] A. R. Chowdhury and S. Banerjee, "Towards an automated approach to the detection of retinal abnormalities," CSI Transactions, vol. 5, no. 1, pp. 71-78, 2017.

[22] S. Akbar, et al, "Decision Support System for Detection of Papilledema through Fundus Retinal Images," Journal of Medical Systems, vol. 41, no. 4, pp. 1-16, 2017.

[23] S. Khalid, et al, "Automated Segmentation and Quantification of Drusen in Fundus and Optical Coherence Tomography Images for Detection of ARMD,” Journal of Digital Imaging, pp. 1-13, 2017.

[24] N. A. Vijapur and R. S. R. Kunte, "Sensitized Glaucoma Detection Using a Unique Template Based Correlation Filter and Undecimated Isotropic Wavelet Transform," Journal of Medical and Biological Engineering, vol. 37, no. 3, pp. 365-373, 2017.

[25] M. N. Zahoor and M. M. Fraz, "Fast Optic Disc Segmentation in Retinal Images Using Polar Transform," Fast Optic Disc Segmentation in Retinal Images Using Polar Transform. In: Valdés Hernández M., González-Castro V. (eds) Medical Image Understanding and Analysis. MIUA 2017. Communications in Computer and Information Science, vol. 723. Springer, Cham, pp. 38-49, 2017.

[26] M. S. Haleem, et al, "A Novel Adaptive Deformable Model for Automated Optic Disc and Cup Segmentation to Aid Glaucoma Diagnosis,” Journal of Medical Systems, vol. 42:20, pp. 1-18, 2018.

[27] B. Karasulu, "An Automatic Optic Disk Detection and Segmentation System using Multi-level Thresholding," Advances in Electrical and Computer Engineering, vol. 14, no. 2, pp. 161-172, 2014.

[28] N. Mukherjee and H. S. Dutta, "Automated localization of optic disk in retinal fundus images using cluster region membership and vessel network," IETE Journal of Research., Feb 2018.

[29] N. Panwar, et al, "Fundus Photographyy in the 21st Century-A Review of Recent Technological Advances and Their Implications for Worldwide Healthcare," Telemedicine Journal and E-Health, vol. 22, no. 3, pp. 198-208, 2016.

[30] Kowa Nonmyd7. Available at http://www.kowa.co.jp/e-life/product/nonmyd7.htm (last accessed Feb. 13, 2018).

[31] E.L. Kim and A.A.M. Moshfeghi, "Wide-field Imaging of Retinal Diseases," US Ophthalmic Review, vol. 8, no. 2, pp. 125-31, 2015.

[32] M.D. Abramoff, et al, "Retinal Imaging and Image Analysis," IEEE Trans Med Imaging, vol. 3, pp. 169-208, 2010.

[33] L.V. Johnson, "Secondary Reseptor Degerations: Age-Related Macular Degeneration," In: J.C. Besharse and D. Bok, the Retina and Its Disorders, Kidlington, Oxford: Elsevier, pp. 830-835, 2011.

[34] S. Hirano and S. Tsumoto, "Rough representation of of a region of interest in medical images," International Journal of Approximate Reasoning, vol. 40, pp. 23-34, 2005.

\section{BIOGRAPHIES OF AUTHORS}
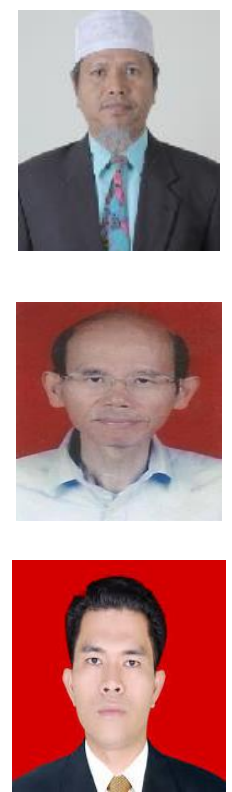

Jufriadif Na`am was born in Padang, Indonesia, in 1967. He is an Assoc. Prof. in Computer Science Department, Universitas Putra Indonesia YPTK. He received the Bachelor Degree in Management Informatics and Master Degree in Information Tecnology in 1994 and 2006 from Universitas Putra Indonesia YPTK. Moreover, he completed his Doctorate of Information Technology as Medical Image expertise from Gunadarma University in 2017. He is member of IEEE (94313333) and Scopus id is 57189371499 (h-index: 3). Currently, he has been researching on Algorithms and Medical Images. E-mail: jufriadifnaam@gmail.com

Johan Harlan is a medical doctor, professor in medical informatics and head of reseach center of medical informatics of Gunadarma University Jakarta. He obtained his PhD in 2003 and has been the lecturer in doctoral department of information technology of Gunadarma University since 2004. He was one of the founders of Indonesian Health Informatics Association in 2005. Scopus id is 56156931200 (h-index: 3). His area of expertise encompasses medical statistics and clinical epidemiology. E-mail: harlan_johan@ hotmail.com

Irawadi Putra was born in Jakarta, Indonesia, in 1980. He obtained his Ophthalmologist in 2018 from Andalas University Padang. In 2010 until now, he is working at Rumah Sakit Stroke Nasional (RSSN) Bukittinggi, Indonesia. He has expertise in retinal diseases diagnosis. E-mail: irawadiputra@gmail.com 


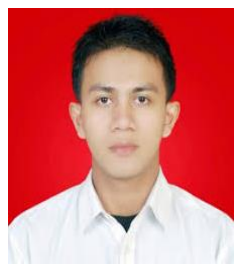

Romi Hardianto was born in Bawan, Indonesia, in 1990. He is a computer lecturer at Universitas Putra Indonesia YPTK. Obtained his Bachelor Degree in Informatics Engineering and Master of Information Technology in 2013 and 2015 from Universitas Putra Indonesia YPTK. E-mail: romihardianto@upiyptk.ac.id

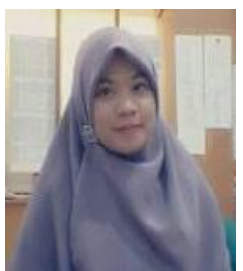

Mutiana Pratiwi was born in Padang, Indonesia. 1991. She is a computer lacturer at Universitas Putra Indonesia YPTK Padang. She obtained bacelor degree in information technology and master of information technology in 2013 and 2015 from Universitas Putra Indonesia YPTK Padang. Currently, she has a researcher on Department of Research, Universitas Putra Indonesia YPTK Padang. E-mail : mutianapratiwi26@gmail.com 